\title{
Cost-minimised design of a highly renewable heating network for fossil-free future
}

\author{
Asad Ashfaq ${ }^{\mathrm{a}, \mathrm{b}, *}$, Anton Ianakiev ${ }^{\mathrm{a}}$ \\ ${ }^{a}$ Department of Civil Engineering, Nottingham Trent University, NG1 $4 F Q$ Nottingham, United Kingdom \\ ${ }^{b}$ Department of Engineering, Aarhus University, Inge Lehmanns Gade 10, 8000 Aarhus C, Denmark
}

\begin{abstract}
This research presents technical and cost-minimised design to decarbonise the heating network by using large-scale heat pump and thermal heat storage. In this paper, real hourly heat-consumption and heatproduction cost data for the city of Aarhus, Denmark are used for calculating techno-economic feasibility of coupling the heating network with electrical grid. An optimum solution is suggested for the entire network with least amount of backup generation capacity, thermal heat storage capacity, natural gas boiler capacity and levelised cost of energy. Aarhus constitutes 5\% of the Denmark's total heat demand and $4 \%$ of electrical load demand. This can be fulfilled with $160 \mathrm{MW}$ of rated wind generation capacity, $35 \mathrm{MW}$ of solar PV generation capacity, $45 \mathrm{MW}$ of backup generation capacity, $221 \mathrm{MW}$ of natural gas boiler capacity and $3.4 \mathrm{GWh}$ of thermal heat storage capacity. The levelised cost of energy shows that, the coupling between the electrical grid and heating sector reduces the cost by more than $50 \%$ to $45 €$ /MWh. However, the cost-minimised design is possible with wind/solar mix of $85 \%$ and renewable energy penetration of $100 \%$. Sensitivity analysis concedes that, the $100 \%$ decarbonisation of heating sector relies heavily upon the cost assumed for wind generation and solar PV generation, instead of the operation and maintenance cost for heat pump. Furthermore, the reduction in cost for wind generation and solar PV generation leads to the decrease in levelised cost of energy. Whereas, the reduction in cost for heat pump, thermal heat storage capacity and natural gas boiler capacity leads to an increase in renewable energy penetration. Sensitivity analysis further reveals that, increasing thermal heat storage capacity and the cost of selling excess renewable energy does not have major impact upon the levelised cost of energy and can be instrumental for the economic viability of fossil-free future.
\end{abstract}

Keywords: Renewable energy, excess generation, heat pump, thermal heat storage, heat coupling, sensitivity analysis.

\section{Introduction}

With the Paris agreement (COP21) intact, the global reduction in greenhouse gas (GHG) emissions have become the key goal in transition towards the clean, sustainable and low-cost energy systems 1. Several energy statistics exhibit that the United States, European Union (EU-28), China and India are accountable for $61 \%$ of all global emissions [2]. The EU is also determined to make radical

\footnotetext{
${ }^{*}$ Corresponding author

Email address: asad_ashfaq2000@yahoo.com (Asad Ashfaq )

${ }^{1}$ Department of Civil Engineering, Nottingham Trent University, NG1 4FQ Nottingham, United Kingdom

reduction in GHG emissions primarily through the electrification of the heating sector by 2050 [3. In recent studies, Lund et al. 44 have discussed the important relationship between smart energy systems and heating network and Markovska et al. [5] have elaborated the main challenges of energy supply security in twenty-first century. Likewise, Connolly et al. [6] have provided the detailed mapping of EU heat demand and identified the potential for district heating by 2050. Lund et al. [7, 8, have discussed that the heating network contributes more to energy-losses than the electrical grid network and therefore, the forefront in achieving future targets of $\mathrm{CO}_{2}$ emissions reduction should be the decarbonisation of heating sector. 


\begin{tabular}{|c|c|c|c|}
\hline \multicolumn{4}{|c|}{ Nomenclature } \\
\hline$\alpha^{W}$ & $\begin{array}{l}\text { share of wind generation in total renew- } \\
\text { able energy generation }\end{array}$ & $\begin{array}{l}Q_{s h} \\
r\end{array}$ & $\begin{array}{l}\text { space-heat demand } \\
\text { discount rate }\end{array}$ \\
\hline$\Delta_{E}$ & electrical mismatch & $T$ & lifetime of technology \\
\hline$\Delta_{H}$ & heat mismatch & $t$ & index representing hour in a year \\
\hline$\gamma$ & $\begin{array}{l}\text { gross share of renewable energy penetra- } \\
\text { tion }\end{array}$ & $V$ & net-present value \\
\hline $\mathcal{K}^{B}$ & backup generation capacity & $V_{\text {elec }}$ & $\begin{array}{l}\text { net-present value of electrical grid tech- } \\
\text { nologies }\end{array}$ \\
\hline $\mathcal{K}^{E}$ & thermal heat storage capacity & & \\
\hline $\mathcal{K}^{N}$ & household natural gas boiler capacity & heat & nologies \\
\hline $\begin{array}{l}\langle.\rangle \\
P\end{array}$ & time average of all 8760 hours in an year & CCGT & combined cycle gas turbines \\
\hline B & backup generation & $\mathrm{COP}$ & coefficient of performance \\
\hline $\begin{array}{l}E \\
G\end{array}$ & $\begin{array}{l}\text { energy content from thermal heat } \\
\text { generation }\end{array}$ & $\mathrm{DC}$ & Direct current electrical grid \\
\hline$G^{S}$ & solar PV power generation & $\mathrm{DH}$ & district heating network \\
\hline$G^{W}$ & wind power generation & DHW & $\begin{array}{l}\text { hot-water required for household activi- } \\
\text { ties }\end{array}$ \\
\hline$L_{E}$ & electrical load demand & HP & large-scale heat pump \\
\hline$L_{H}$ & heat demand & LCOE & levelised cost of energy \\
\hline$N$ & $\begin{array}{l}\text { energy content from household natural } \\
\text { gas boiler }\end{array}$ & $\mathrm{PV}$ & solar photo-voltaic \\
\hline$P^{e x}$ & excess generation & $\mathrm{SH}$ & space-heat required to heat buildings \\
\hline$Q_{d h w}$ & domestic hot-water demand & TES & centralised thermal heat storage \\
\hline
\end{tabular}

Furthermore, Mathiesen et al. 9] and Connolly et al. 10 have presented the technical-economic aspects of $100 \%$ renewable energy based smart energy systems for the EU and suggested the interconnection between multiple energy sectors as well as implementation of coherent smart energy system approach for the least cost solution. Hansen et al. 111] and Xiong et al. [12] have provided a comprehensive heat road-map strategy for achieving energy efficiency in the heating sector in Europe and China, respectively. Few researchers have also presented geographical Atlases for the spatial distribution of heat demand in Europe. Persson et al. [13. have quantified the voulume of excess heat in EU countries and Möller et al. [14 have calculated the heat demand as per-building level. Ashfaq et al. 15. have mapped the energy saving potential with the implementation of district heating networks and heat pump technologies. Petrovic et al. [16] have provided a comprehensive insight for heat Atlas as a tool for exploring different renewable energy scenarios.

Furthermore, Grundahl et al. [17] and Dominković et al. [18 have investigated case studies for the Danish heating network and concluded that, the future expansion of district heating networks into heating grids along with the integration of waste heat sources is the only way forward towards the economic feasibility. Thellufsen et al. [19] have studied the Danish energy systems and calculated that the energy saving benefits are more with the synergy of both electrical and heating networks. Ashfaq et al. [15] have discussed the significance for utilisation of excess renewable energy generation into decentralised municipal district heating networks. Rolando et al. 20. have recommended the cross border interconnection of electrical grids, whereas Thellufsen et al. 21] have suggested the 
cross sector interconnection of renewable energy sources for increasing the efficiency of European energy systems.

The current heating network is mostly supported by the co-generation of heat and power plants (CHP) or stand-alone fossil-fuel boiler systems. While, taking them out of the network without techno-economic feasibility analysis will have a massive impact. Pensini et al. 22] has calculated the cost-effectiveness for the electrification of heating sector in PJM interconnection of United States, but still there is limited knowledge regarding the economic feasibility for the transition of European energy system. This research addresses these issues and fills-in vital gap by providing a combined techno-economic analysis and investigates:

- Will the coupling of heat and electricity sector be techno-economic feasible?

- What will be the hourly intra-day energy trend of heat demand, thermal heat storage and natural gas boiler profile through-out the year?

- Will the heat-coupling be cost-effective in comparison to the current conventional heating network?

- How does the variations in renewable energy penetration $(\gamma)$ and wind/solar mix $\left(\alpha^{W}\right)$ affect the levelised cost of energy (LCOE)?

- What is the optimum strategy for the decarbonisation of heating network by electrification?

In this paper, the concept of fully renewable electrical grid and heating network based on fluctuating weather patterns is introduced for the decarbonisation of heating network. The technical analysis is done by analysing the hourly actual intra-day energy demand profiles and heat-consumption data. The economic-analysis is performed by calculating LCOE for the proposed energy system and compared with the current heat-production cost from conventional sources. Later, a sensitivity analysis is performed to find the cost-minimised configuration with variations in cost-assumption, renewable energy penetration $(\gamma)$ and wind/solar mix $\left(\alpha^{W}\right)$. In the end, the technology which defines the costminimised solution is identified.

The paper proceeds as follows: the methodology for techno-economic analysis of electrical grid, heating network and cost modelling is discussed in Sections 2.1, 2.2 and 2.4, respectively. Then, results for the technically optimal network with reduced backup generation capacity, thermal heat storage capacity and natural gas boiler capacity are provided in Section 3.1 and the LCOE for economically optimal network configuration with variation in renewable energy penetration and wind/solar mix is calculated in Section 3.2 Subsequently, the sensitivity analysis is performed to analyse the effect on the cost-minimised design solution with variations in cost assumption for different technologies in Section 4.1. Finally, the effect with selling excess generation and results for the cost-effective strategy are concluded in Sections 4.3 and 5 respectively.

\section{Methods and modelling}

This analysis considers a futuristic highly renewable energy based network, where the wind and solar PV are taken as renewable energy sources and other sources are assumed as instantaneous backup power generation sources (conventional energy generation, hydro-electric storage lakes, biomass). The modelling has been divided into two parts: electrical grid modelling and heating network modelling. The electrical grid is assumed to Direct Current (DC) with unconstrained internal transmission and distribution. This is reasonable assumption for DC electrical grid which has insignificant power-losses and motivates removing bottlenecks in the electrical grid. The 8 years (2000-2007) of hourly wind power generation, solar PV generation and electrical load demand time-series for Denmark are directly taken from the ISET data-set 23 and then, scaled to annual electrical load demand of 1,603 GWh for the city of Aarhus, Denmark [24]. The 4 years (2011-2015) of hourly heat-consumption and heat-production cost time-series are taken from the Aarhus Municipality. The geographical distribution of heat demand in Denmark and renewable energy power generation time-series is shown in Fig.1.

\subsection{Electrical load and excess generation modelling}

Electrical load modelling is done by considering the power generation from wind and solar PV power sources at hourly intervals i.e $t$. Both wind and solar PV power generation are normalised to their mean and the symbol $\langle$.$\rangle is used to represent the$ time-average. The share between wind generation $\left(G^{W}\right)$ and solar PV power generation $\left(G^{S}\right)$ in generation $(G)$ is defined by wind/solar mix $\left(\alpha^{W}\right)$. The 

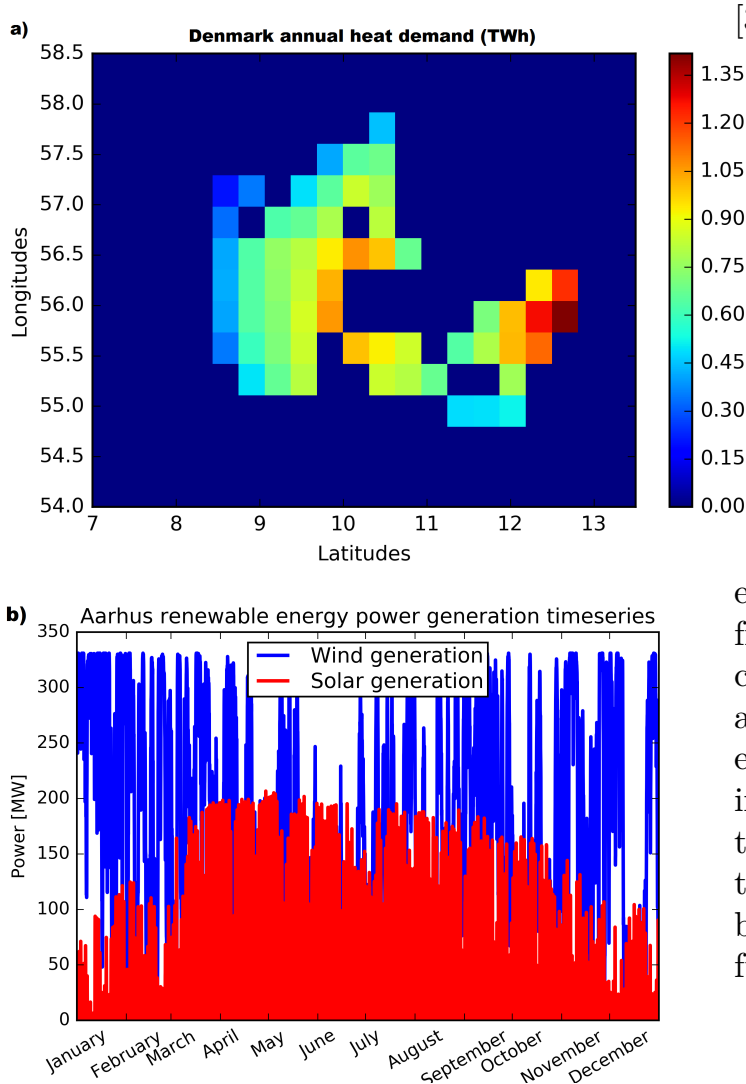

Figure 1: Panel (a) shows geographical annual heat demand $\left(L_{H}\right)$ of Denmark at spatial resolution of $40 \times 40 \mathrm{~km}^{2}$ for the year (2011). Panel (b) shows wind and solar PV power generation time-series for Aarhus, Denmark. The panel (a) results are taken from Ref. [15 and use temperature data from NCEP CFSR 25 26], population data from 27] and heat demand from 28, 29. (For interpretation and reference to the legends in this figure, the reader is referred to the web version of this article.)

gross share of power generation is regulated according to the electrical load demand by using the scaling factor renewable energy penetration $(\gamma)$. The renewable energy penetration $\gamma=1$ and $\gamma=2$ depicts the network modelling with renewable power generation equal or twice than the electrical load demand. This method for the electrical grid modelling is quite robust and used in studies such as; calculating an optimal mix between wind and solar generation [30, 31], identifying battery storage needs in electrical grid [32, 33, impact of transition on pan-European renewable electrical grid 20, 34, 35, feasibility of interconnected fully renewable US electrical grid [36, 37] and calculating backup flexibility in large-scale renewable systems
38.

$$
\begin{gathered}
G(t)=G^{W}(t)+G^{S}(t) \\
\alpha^{W}=\frac{\left\langle G^{W}\right\rangle}{\langle G\rangle} \\
\gamma=\frac{\langle G\rangle}{\left\langle L_{E}\right\rangle} \\
G(t)=\gamma \cdot\left\langle L_{E}\right\rangle\left[\alpha^{W} \cdot G^{W}(t)+\left(1-\alpha^{W}\right) G^{S}(t)\right]
\end{gathered}
$$

These above quantities are useful for calculating excess generation $\left(P^{e x}\right)$ and backup generation $(B)$ from the electrical mismatch $\left(\Delta_{E}\right)$. The electrical mismatch $(\Delta)$ is the difference between generation $(G)$ and electrical load demand $\left(L_{E}\right)$. The excess generation $\left(P^{e x}\right)$ and backup generation $(B)$ in an electrical grid is calculated from intervals with the positive electrical mismatch $\left(\left|\Delta_{E}\right|_{+}\right)$and negative electrical mismatch $\left(\left|\Delta_{E}\right|_{-}\right)$, respectively. The backup generation is the demand which has to be fulfilled by backup power generation sources.

$$
\begin{gathered}
\Delta_{E}(t)=G(t)-L_{E}(t) \\
P^{e x}(t)=\left|\Delta_{E}(t)\right|_{+} \\
B(t)=\left|\Delta_{E}(t)\right|_{-}
\end{gathered}
$$

\subsection{Heating network modelling}

The heat demand $\left(L_{H}\right)$ can be further differentiated into space-heat demand $\left(Q_{s h}\right)$ and hot-water demand $\left(Q_{d h w}\right)$. The integration of electrical grid into heating network is determined by the heat mismatch and its calculation is significant to this research. Heat mismatch $\left(\Delta_{H}\right)$ at hour $(t)$ is the difference between the excess generation $\left(P^{e x}\right)$ from the electrical grid, coefficient of performance (COP) of heat pump and heat demand $\left(L_{H}\right)$ of the heating network.

$$
\begin{gathered}
L_{H}(t)=Q_{s h}(t)+Q_{d h w}(t) \\
\Delta_{H}(t)=P^{e x}(t) * \mathrm{COP}-L_{H}(t)
\end{gathered}
$$

As in Section 2.1, the excess heat energy in heating network is calculated from intervals with positive heat mismatch $\left(\left|\Delta_{H}\right|_{+}\right)$and the heat deficit from intervals with negative heat mismatch 
$\left(\left|\Delta_{H}\right|_{-}\right)$. This excess heat energy can be stored into the thermal heat storage $(E)$ and heat deficit is fulfilled from natural gas boiler $(N)$.

$$
\begin{aligned}
& E(t)=\left|\Delta_{H}(t)\right|_{+} \\
& N(t)=\left|\Delta_{H}(t)\right|_{-}
\end{aligned}
$$

\subsubsection{Bayesian analysis}

The heat-consumption data is taken from the Aarhus Municipality and calculations are performed in two steps. First, the heat-consumption data is compared with heat demand from the geographical heat demand model in Ref. [15] and annual heat demand given in Ref.[24]. Then, the Bayesian analysis is used to remove discrepancies in actual heat-consumption data time-series. The posterior distribution from likelihood and prior is calculated for each hour $(t)$ in time-series by applying the Bayes' theorem in inference.

$$
\begin{gathered}
\text { Posterior }=\frac{\text { likelihood.prior }}{\text { probability }} \\
P(\theta \mid \text { data, model })=\frac{P(\theta \mid \text { data }) \cdot P(\theta \mid \text { model })}{P(\text { data } \mid \text { model })} \\
\text { likelihood }=\frac{1}{\sqrt{2 \pi \sigma^{2}}} \exp \left(-\frac{(X-\mu)^{2}}{\sqrt{2 \sigma^{2}}}\right)
\end{gathered}
$$

It is found by using Eqs. 12, 13 that, the actual heat-consumption data from Aarhus municipality matches closely with geographical heat demand calculation model and errors especially during the summer season are removed significantly. These results from the Bayesian analysis are shown below in Figs 2 and 3 .

\subsubsection{Heat pump coupling}

The excess generation is converted directly into heat by using heat pump based coupling, as shown in Fig. 4 This heat pump coupling considers reasonable energy-losses to get realistic and practical results. It is assumed that, the heat pump has the COP of 3 , both the district heating network and centralised thermal heat storage have an efficiency of $90 \%$ and an on-site natural gas boiler has an efficiency of $100 \%$. These efficiencies for the heat pump coupling are same as for the electrification of heating sector in United States and Europe in Refs. 22 and [15], respectively. This heat-coupling operates with the following priority sequence:
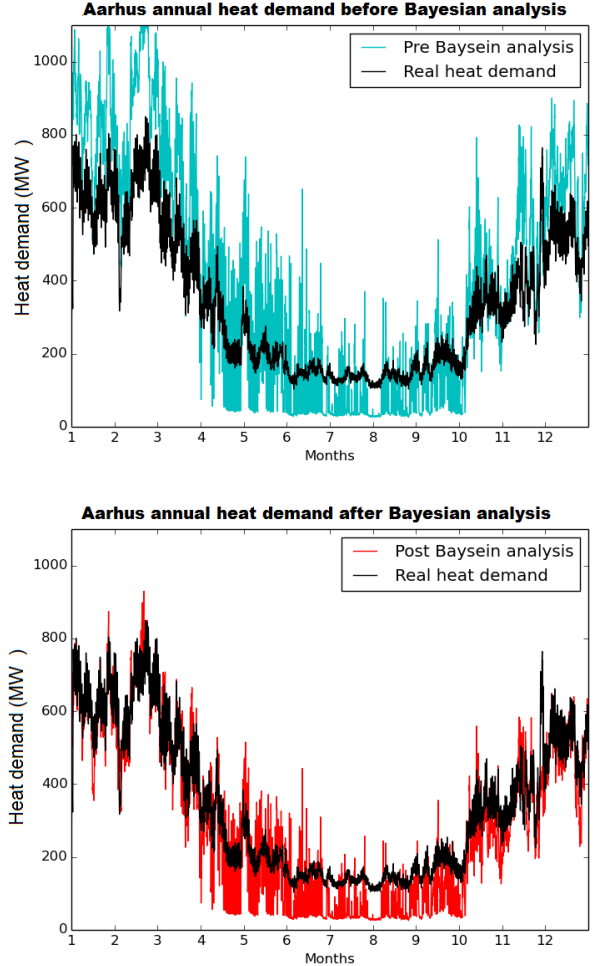

Figure 2: Heat demand time-series for Aarhus, before and after the Bayesian analysis. Results show, errors especially in form of large peaks are removed to a considerable extent.

1. Excess generation from the electrical grid is first processed into heat by the heat pump and then, delivered directly to consumers through the district heating network.

2. In case, if there is less heat demand then the proportion of excess heat in network is stored into the thermal heat storage and used during intervals with no excess generation.

3. Heat from the on-site natural gas boiler is used as a backup, when there is heat deficit in the network and no heat is available from the thermal heat storage.

\subsection{Capacity modelling}

In this modelling, the electrical grid and heating network is altogether supported by three backup technologies; backup generation $(B)$, natural gas boiler $(N)$ and thermal heat storage $(E)$. The capacity of these backup technologies depends upon the renewable energy penetration $(\gamma)$ and wind/solar mix $\left(\alpha^{W}\right)$. The minimum required 
a)
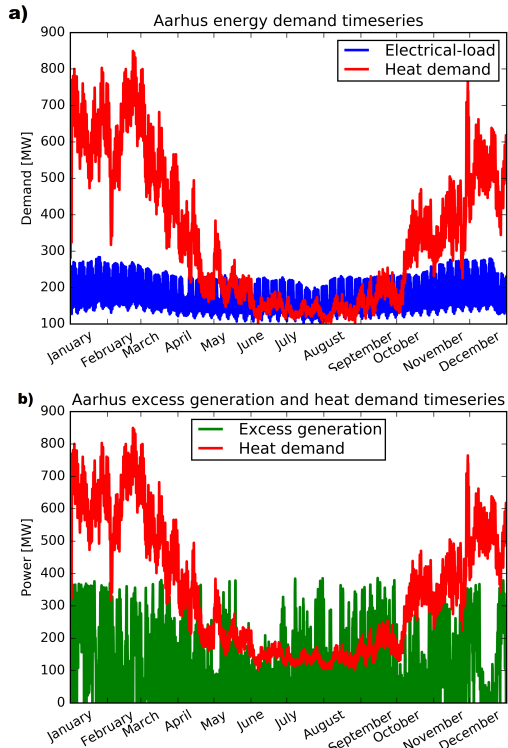

Figure 3: Seasonal electrical load demand $\left(L_{E}\right)$, heat demand $\left(L_{H}\right)$ and excess generation $\left(P^{e x}\right)$ time-series for Aarhus. Panel (a) shows electrical load and heat demand, whereas panel (b) compares the excess generation and heat demand. The excess generation is calculated at renewable energy penetration $(\gamma=1)$ and wind/solar mix $\left(\alpha^{W}=0.8\right)$. These results depict the possibility of utilising excess generation by heating network.

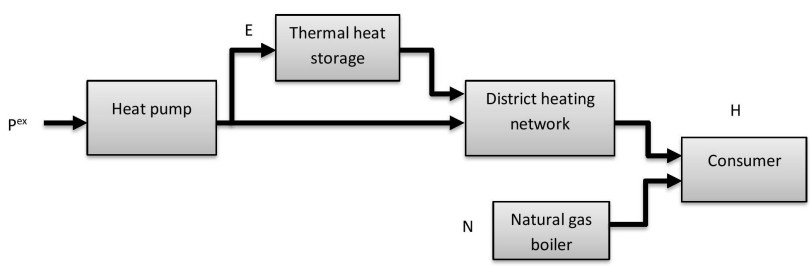

Figure 4: Block diagram of the heat pump coupling.

backup generation capacity $\left(\mathcal{K}^{B}\right)$ and natural gas boiler capacity $\left(\mathcal{K}^{N}\right)$ are calculated from the mean of required energy time-series.

$$
\begin{aligned}
\mathcal{K}^{B} & =\left\langle\sum_{t=1}^{8760} B(t)\right\rangle \\
\mathcal{K}^{N} & =\left\langle\sum_{t=1}^{8760} N(t)\right\rangle
\end{aligned}
$$

The thermal heat storage capacity $\left(\mathcal{K}^{E}\right)$ is calculated by taking the $99 \%$ quantiles of thermal heat storage time-series distribution $p(E)$. The 99\% quantiles are to avoid the impact from severe events. This method for capacity estimation is wellestablished and used in studies [20, 39].

$$
\begin{gathered}
q=\int_{0}^{E} p(E) d E \\
\mathcal{K}^{E}=E^{99 \%}
\end{gathered}
$$

\subsection{Cost modelling}

The levelised cost of energy (LCOE) is the per unit cost of energy produced by a technology over it's lifetime. As compared to the annual cost analysis, LCOE is much roubust method to assess the overall economic feasibility among different technologies. In this research, the cost is assumed to reduce with the maturity of each technology and taken as lowest available in literature. The cost for electrical grid and heating network is taken from Refs. [39, 41] and [3, 8, 22, respectively. This is the same approach as used for pan-European electrical grid by Rolando et al. in Ref. 39.

There are two type of costs associated with any technology i.e. capital expenses (CapEx) and operation \& maintenance (OpEx) expenses. CapEx expenses are usually initial one-time investment costs and also known as the installation costs. The OpEx expenses are additional associated recurring costs during the product's lifetime. These OpEx costs for each technology is further differentiated into fixed and variable OpEx expenses. It is assumed that, the fixed OpEx expenses are the monthly or annual maintenance and repair costs, whereas variable OpEx expenses are fuel costs only, which fluctuate with the fossil-fuel price. The CapEx and OpEx expenses assumed for different technologies in this research are listed in table 1 .

The cost assumed for different technologies of the electrical grid: onshore wind turbine, solar PV and combined cycle gas turbines (CCGT) are the same as assumed for pan-European electrical grid by Rolando et al. in Ref.[39]. The CCGT turbines are chosen for the backup generation as they have higher efficiency, require less maintenance and quick to start. Moreover, the cost assumptions for different technologies of heat-coupling: heat pump, thermal heat storage, district heating and natural gas boiler are the same as assumed for PJM interconnection of United States in Ref. [22].

In calculations, the cost for excess generation in stand-alone electrical grid is calculated from the remaining excess proportion of wind and solar PV power generation. The discount rate is taken as $4 \%$ 
and the heat pump is with a reasonable COP of 3. These parameters are same as in Refs. [22, 39]. Moreover, CapEx expenses for the district heating network is ignored as the city of Aarhus, Denmark has already got a well-developed district heating network. Furthermore, the variable OpEx expenses for CCGT turbines and natural gas boiler are assumed to remain constant for the next 30 years i.e. 56 and $17 € / M W h$, respectively. Even-though, the recent forecasts show that it will not be increasing in future [39]. This is done to get realistic and worst case scenario results. The cost for all technologies is calculated by estimating capacities required to fulfill energy demand of the network and net-present value of future expenses. The net-present value $(V)$ from CapEx and OpEx expenses with the discount rate $(r)$ of $4 \%$ is calculated as,

$$
\begin{gathered}
\text { Cost }_{\epsilon / t}=\text { Power }_{\mathrm{MWh} / t} \cdot \text { Cost }_{\epsilon / \mathrm{MWh}} \\
V=\mathrm{CapEx}+\sum_{t=1}^{T} \frac{\mathrm{OpEx}_{t}}{(1+r)^{t}} \\
V_{\text {elec }}=V_{G^{W}}+V_{G^{S}}+V_{B} \\
V_{\text {heat }}=V_{H P}+V_{E}+V_{D H}+V_{N}
\end{gathered}
$$

where, $V$ is the net-present value, $T$ is the lifetime of technology and $r$ is the discount rate. $V_{\text {elec }}$ considers the net-present value for electrical grid technologies: onshore wind turbines $\left(G^{W}\right)$, solar PV $\left(G^{S}\right)$ and CCGT turbines $(B)$. Whereas, $V_{\text {heat }}$ considers the net-present value for heat-coupling technologies: heat pump (HP), thermal heat storage $(E)$, district heating network $(\mathrm{DH})$ and natural gas boiler $(N)$. The LCOE for each network is calculated as,

$$
\begin{gathered}
V_{\text {sys }}=V_{\text {elec }}+V_{\text {heat }} \\
\mathrm{LCOE}=\frac{V_{\text {sys }}}{\sum_{t=1}^{T} \frac{L_{t}+H_{t}}{(1+r)^{t}}}
\end{gathered}
$$

The LCOE divides total cost of energy generation from different sources to the sum of total energy demand during the lifetime 39 . In eq (23), $V_{\text {sys }}$ is the net-present value of power generation cost discounted to the future value and denominator is the discounted future energy demand. It is important to realise that, the wind and solar PV generation are two main power generation sources, whereas CCGT turbines, thermal heat storage and natural gas boiler are only available as backup power generation sources.

Table 1: Cost (CapEx and OpEx), lifetime and efficiency assumed for different technologies. The cost for electrical grid and heating network is taken from Refs. 39,41] and 3. 8. 22, respectively. These costs are used for calculating netpresent value and levelised cost of energy by using Eq. 23. with discount rate of $4 \%$.

\begin{tabular}{llll}
\hline Technologies & $\begin{array}{l}\text { CapEx } \\
\text { Fixed }\end{array}$ & OpEx & \\
\cline { 3 - 4 } & {$[€ / \mathrm{W}]$} & {$[€ / \mathrm{KW} /$ year $]$} & $\begin{array}{l}\text { Variable } \\
{[€ / \mathrm{MWh}]}\end{array}$ \\
\hline Wind turbines - onshore & 1.0 & 15.0 & - \\
Solar photo-voltaic $(\mathrm{PV})$ & 1.5 & 8.5 & - \\
CCGT turbines & 0.90 & 4.5 & 56 \\
Heat pump & 0.61 & 4.3 & - \\
Thermal heat storage & 0.0027 & 0.03 & - \\
District heating network & - & 2 & - \\
Natural gas boiler & 0.18 & 9.5 & 17.0 \\
\hline
\end{tabular}

\section{Analysis and discussion}

This section present results and findings from this research. First, the scope of simulations for the technically optimal network is discussed by analysing hourly energy trend of intra-day demand profile throughout the year. Then, the required capacities for backup generation, thermal heat storage and natural gas boiler with the integration of heat pump coupling are calculated. Subsequently, the economic feasibility for the optimally configured network is found and compared with the actual heat-production cost of conventional fossil-fuel based district heating network.

\subsection{Technically optimal network}

The technical behaviour with integration of heat pump coupling into the network is analysed by investigating energy time-series. The analysis reveals that, the excess heat is often available in thermal heat storage during the summer season and rarely in winter season. On the other-hand, the need for backup heat from natural gas boiler is high during the winter season. This suggests that, the current amount of excess generation is enough for the summer season, but can not fully support the heating network in winter season. 
Furthermore, designing the thermal heat storage according to $99 \%$ qualities of the thermal heat storage time-series distribution by using the Eq. 177 is found to be practically advantageous than designing natural gas boiler at mean of required energy time-series, especially during the winter season. However, if the current amount of excess generation is increased beyond renewable energy penetration $(\gamma)$ of 1.4 and wind/solar mix $\left(\alpha^{W}\right)$ is greater than 0.6 , then the natural gas boiler can be designed at mean energy capacity. This aspect of excess generation is similar to findings in [15, 22. These results are shown and compared in Fig 5

\subsubsection{Intra-day profile analysis}

It is significant to analyse the intra-day heat demand profile for planning and forecasting purposes, as the heat demand varies throughout the day apart from seasonal variations. Interestingly, results show the intra-day heat demand profile coincides with people commute to work. The heat demand is found to be maximum at $9 \mathrm{hrs}$ in the morning, when people are leaving for work and it sharply decreases afterwards. Later, the heat demand increases again between 15 - 19 hrs when people are returning to home and ultimately lowest at $1 \mathrm{hrs}$ during the night. It is observed that, the heat demand on average varies between $310 \mathrm{MWh}$ and 380 MWh during the day. The heat demand is highest from January to March and lowest from June to August. These results for the intra-day profile are shown in Fig, 6 .

The excess generation, on the other hand show trend opposite to the heat demand and similar to the solar PV power generation. The excess generation increases with the sunshine and maximum at 13 hrs around noon. Then, it sharply decreases to the lowest level at $18 \mathrm{hrs}$ around sunset. The excess generation on average varies between $30 \mathrm{MWh}$ and $90 \mathrm{MWh}$ during the day. This is due to the fluctuating nature of wind and solar PV power generation. The excess generation is highest during months from March to May and lowest from November to December. This fluctuating and opposite trend of heat demand and excess generation provides with excellent opportunity to generate heat from the excess generation and storage in thermal heat storage. This further validates the trend earlier shown in Fig, 3

The excess heat in thermal heat storage show similarity with excess generation in the network. The thermal heat storage is lowest in the morning due to high heat demand. Later, the heat in thermal heat storage increases to the maximum level between 15 - $16 \mathrm{hrs}$ and later starts decreasing gradually in the evening. The heat in thermal heat storage on average varies between $220 \mathrm{MWh}$ and 470 MWh during the day. The analysis of excess heat available in thermal heat storage throughout the year confirms, that it's highest during months from April to June and lowest from October to December.

The backup heat from natural gas boiler behaves similar to the heat demand. The heat required from natural gas boiler is maximum at $8 \mathrm{hrs}$ in the morning and minimum at $1 \mathrm{hrs}$ when people are sleeping. It can be understood that, this increase in backup heat in the morning is due to absence of heat from the thermal heat storage. Later, the required backup heat decreases sharply and increases again between 12 - 15 hrs. However, this time the heat demand is partially compensated by thermal heat storage and the required backup heat is not maximum. The backup heat from the natural gas boiler on average varies between $170 \mathrm{MWh}$ and 280 MWh during the day. The analysis of backup heat from natural gas boiler throughout the year confirms, it is highest during months from January to March and lowest from June to August.

It is concluded that, the carbon-neutral future with heat-coupling is possible, but this will lead to more peaks in heat demand compared to the current conventional heating network unless, techniques such as, changing consumers behaviour, demand side management, energy from other sources or waste heat from the industry are utilised.

\subsubsection{Minimum capacity analysis}

The detailed overview of backup capacity required by networks for three scenarios with different proportion of renewable energy penetration and wind/solar mix is shown in Fig,7. The three columns represent different scenarios of renewable energy penetration $(\gamma)$ and rows represent the corresponding behaviour with variation in wind/solar $\operatorname{mix}\left(\alpha^{W}\right)$. Interestingly, the backup generation capacity and natural gas boiler capacity show strong dependence on the renewable energy penetration $(\gamma)$. However, the thermal heat storage capacity depends upon variation in the wind/solar mix $\left(\alpha^{W}\right)$, as shown in Fig,7.

The middle column in Fig 7 depicts scenario, when the renewable energy penetration is equal to electrical load demand $(\gamma=1)$. It is observed 
that, both backup generation capacity and thermal heat storage capacity reduces with the increase in wind/solar mix and found to be minimum at $\alpha^{W}=$ 0.8 . Whereas, the natural gas boiler capacity initially increases with wind/solar mix and then starts decreasing after the wind/solar mix $\alpha^{W} \geq 0.6$. The natural gas boiler capacity is minimum at wind only $\operatorname{mix}\left(\alpha^{W}=1\right)$. This behaviour of capacities is similar to that observed in Refs. [15].

The right column in Fig.7 depicts scenario, when the renewable energy penetration $(\gamma)$ is increased by $50 \%$. Interestingly, the backup generation capacity and natural gas boiler capacity reduces significantly. However, there is noticeable increase in thermal heat storage capacity, which can be understood due to the increase in excess generation. It is observed that, the required energy capacities decrease with the increase in wind/solar mix and minimum at $\alpha^{W}=0.8$. Nevertheless, the left column in Fig.7. when the renewable energy penetration $(\gamma)$ is decreased by $50 \%$ confirms, that there is abrupt increase in required backup generation capacity and natural gas boiler capacity. Whereas, the thermal heat storage is either non-existent or insignificant.

It is concluded that, the scenario with renewable energy penetration $\gamma \geq 1.5$ and wind/solar mix $\alpha^{W}$ $=0.8$ is the most viable option, as both required backup generation and natural gas boiler capacities are minimum and the excess heat for thermal heat storage capacity is also available. The economic analysis for the above three scenarios is discussed in sections below.

\subsection{Economically optimal network}

As discussed in Section 3.1, both electrical grid and heating network are expensive during the summer season and their integration is beneficial in mitigating seasonal variations. The economic feasibility of coupled network is analysed by calculating LCOE from Eq. 23 as an economic objective. It is calculated from the required capacities found in Section 3.1.2 and costs (CapEX and OpEX) assumed for different technologies given in table 1 .

The annual heat demand including space-heat and hot-water demand of Aarhus is 2.9 TWh, which constitutes $5 \%$ of Denmark's total heat demand of 57.9 TWh. This heat demand of 2.9 TWh is generated from the combined heat and power (CHP) plant with an average heat-production cost of 40 $€ / \mathrm{MWh}$ and delivered to consumers through the district heating network. It is calculated that, if the heat pump coupling is installed then approximately 2.2 millions $€$ annual worth of heat can be supplied from the thermal heat storage. This is shown below in Fig.8

The detailed LCOE for different technologies in the network and their share towards the total cost $€ / M W h$ is shown below in Fig 9 The three columns represent different scenarios of renewable energy penetration $(\gamma)$ and rows represent different networks with variation in the wind/solar $\operatorname{mix}\left(\alpha^{W}\right)$. The first row represent results for the fully renewable energy based stand-alone electrical grid, second row for the heating network with heatcoupling and the third row when both networks are coupled together.

The middle column in Fig 9 exhibit results, when the renewable energy penetration $(\gamma=1)$ is equal to the electrical load demand. It is calculated that, the fully renewable based electrical grid can be supported with the minimum LCOE of $120 € / \mathrm{MWh}$. The LCOE for fully renewable energy based electrical grid and heating network with heat pump coupling varies between $120-170 € /$ MWh and $18-28$ $€ / M W h$, respectively. However, when both networks are coupled together then it varies between $45-65 € / \mathrm{MWh}$. It is found that, the cost of energy from natural gas boiler in this scenario is higher than heat pump, which can be understood as less amount of excess generation is available.

The analysis with both networks coupled together confirms, that the energy cost can be reduced by more than $50 \%$ to approximately 45 $€ / M W h$, rather than the current conventional heating network of $40 € / M W h$. Furthermore, the LCOE for both electrical grid and heating network reduces with increase in the share of wind generation. Although, the OpEx expenses for onshore wind turbines is almost twice than the solar PV, but the LCOE is found to be minimum at wind/solar $\operatorname{mix}$ of $\alpha^{W}=0.85$.

The right column in Fig 9 exhibit results, when the renewable energy penetration $(\gamma \geq 1.5)$ is increased by $50 \%$ more than the electrical load demand. The LCOE for the electrical grid and heating network varies between $180-260 € /$ MWh and $28-35 € / M W h$, respectively. It is calculated that, the coupling of both networks reduces the cost to 65 - $80 € /$ MWh. In comparison to above results, this increase in energy cost at renewable energy penetration $(\gamma \geq 1.5)$ is due to increase in power generation cost in the electrical grid and heat pump cost in the heating network. The LCOE for electrical grid and 
heating network is found to be minimum at $\alpha^{W}=$ 0.8 and 0.7 , respectively. Nevertheless, when both networks are coupled together, then the LCOE is minimum at $\alpha^{W}=0.80$.

The left column in Fig 9 exhibit results, when the renewable energy penetration $(\gamma \leq 0.5)$ is decreased by $50 \%$. The cost of backup generation and natural gas boiler increases significantly and the cost for heat pump and district heating network are nonexistent. Nevertheless, the LCOE is minimum at the wind only $\operatorname{mix}\left(\alpha^{W}=1\right)$.

It is concluded that, the LCOE is minimum when both electrical grid and heating networks are coupled together. The cost-optimum as well as the reliable solution for fossil free future is found at the renewable energy penetration $(\gamma \geq 1.5)$ and wind/solar mix $\alpha^{W}=0.8$. In-future, the cost for fully renewable energy based stand-alone electrical grid will be increased beyond $260 € /$ MWh. This will hinder the further penetration of renewable energy sources into electrical grid, due to the costcompetitiveness with conventional power generation sources. However, if both electrical grid and heating network are coupled together then the energy costs can be reduced by more than $50 \%$.

The above economic analysis has been done by calculating LCOE from cost assumptions given in the table 1. Nevertheless, results from the economic analysis alone can be misleading, as they depend upon the cost of different technologies. Therefore, sensitivity analysis has been performed in the next section for calculating effect with variation in cost assumptions.

\section{Sensitivity analysis}

This section first discusses results from the economic analysis and effects with future cost variations by sensitivity analysis. Then, the increase in LCOE with respect to renewable energy penetration $(\gamma)$ is analysed for each technology. Finally, the LCOE with possibility of selling excess generation is calculated.

\subsection{Effect of cost-variation}

In this section, the sensitivity analysis is performed by considering six different scenarios and the cost-minimised configuration is calculated. The cost assumed for each technology is different in each scenario and the optimum renewable energy penetration $(\gamma)$ as well as wind/solar mix $\left(\alpha^{W}\right)$ with minimum LCOE is calculated. The cost assumption for technologies in the electrical grid are kept constant in four scenarios and assumptions for technologies in the heating network is kept constant in only two scenarios. This is done as the focus of study is on the heating network, as shown in Fig 10

This effect of variations in cost assumption on LCOE is calculated by considering high - low assumptions in the sensitivity analysis. Instead of making own assumptions, the CapEx and OpEX costs, capacity factors, lifetimes are taken from previously done studies mentioned earlier in Section. 2.4. This extends and adds value to the knowledge of already done findings as well as provide more realistic results which can be compared.

The LCOE calculated in Ref. 42 is approximately $50 \%$ lower than that assumed in Ref. [43. Likewise, the costs (CapEx and OpEX) assumed for the onshore-wind turbines and solar PV in Refs. [42, 44] are almost $25 \%$ and $80 \%$ less than that assumed in Refs. [43, 45]. Moreover, the assumed capacity factor and technology lifetimes are different in Refs. 44, 46, 47, respectively. These variations in cost assumption are often overlooked and makes the comparison between LCOE among studies bit difficult. This issue with economic analysis is the same as highlighted earlier in Ref. 39.

The first scenario in Fig, 10 is based upon the initial cost assumptions (CapEx and OpEX) and the LCOE varies between $45-65 € / M W h$. In the second and third scenarios, when the cost for different technologies in electrical grid and heating network are reduced separately by $50 \%$, then the costminimised solution can be achieved at $28 € / \mathrm{MWh}$ and $39 € / \mathrm{MWh}$, respectively. However, the reduction in cost assumed for technologies of heating network favours the renewable energy penetration into the network.

In fourth scenario of Fig, 10 , when costs for both electrical grid and heating network are increased by $50 \%$ simultaneously, then the cost-minimised solution is achieved at $41 € / \mathrm{MWh}$ and the optimum configuration of renewable energy penetration is reduced to $\gamma=0.8$. In fifth and sixth scenarios, when the cost for the heat pump and natural gas boilers is increased separately by $50 \%$, then the costminimised solution can be achieved at $50 € / \mathrm{MWh}$ and $52 € / M W h$, respectively. Nevertheless, there is noticeable difference observed in the optimum renewable energy penetration.

It is concluded that, the cost-minimised solution is found to be possible at $45 € / \mathrm{MWh}$ with the opti- 
mum configuration of renewable energy penetration $\gamma=1$ and wind/solar mix $\alpha^{W}=0.85$. The share of renewable energy penetration $(\gamma)$ is strongly dependent on the cost assumed (CapEx and OpEX) for different technologies in the heating network, whereas the wind/solar mix $\left(\alpha^{W}\right)$ is independent. This can be noticed from fact that, the increase in cost for heat pump reduces the renewable energy penetration to shallow side $(\gamma=0.8)$ and variations in cost for natural gas boiler increases the renewable energy penetration $(\gamma)$. It is interesting to observe that, the reduction in cost for technologies in the electrical grid results into minimum possible LCOE, but the optimum share of renewable energy penetration is always reduced to $\gamma=0.8$ and wind/solar mix varies between $\alpha^{W}=0.8-0.94$, respectively. These results are further elaborated in Fig. 10

\subsection{Effect of renewable energy penetration}

In this section, the LCOE for individual technology with the increase in renewable energy penetration $(\gamma)$ is discussed. The power generation cost for the solar PV and onshore wind turbine varies up to $45 € /$ MWh and $130 € /$ MWh, respectively. While, the cost of excess generation and backup generation increases with the renewable energy penetration $(\gamma)$ from $2-90 € /$ MWh and decreases from $60-5$ $€ / M W h$, respectively. It is observed that, the cost of excess generation increases abruptly after the renewable energy penetration $(\gamma \geq 0.6)$. Whereas, the cost for excess generation and backup generation are equal at the renewable energy penetration $(\gamma=0.9)$. The LCOE for the electrical grid varies between $60-260 € / \mathrm{MWh}$ and the optimum configuration for stand-alone fully renewable energy based electrical grid is found to be at around renewable energy penetration $\gamma=0.94$. These results are similar to ones discussed for the pan-European electrical grid by Rolando et al. in [39].

Furthermore, the major share of cost in LCOE in the heating network is initially from natural gas boiler, while the share of heat pump, thermal heat storage and district heating network is almost nonexistent. Nevertheless, once the renewable energy penetration $(\gamma)$ increases, then the cost of heat pump increases from $2-26 € / \mathrm{MWh}$ and the cost of natural gas boiler reduces from $18-4 € / \mathrm{MWh}$. Likewise, the cost of thermal heat storage and district heating network increases with renewable energy penetration $(\gamma \geq 0.6)$, but to the maximum of around $2 € / \mathrm{MWh}$. The LCOE of heating network with the heat-coupling is calculated to be varying between $18-34 € / M W h$. These results are shown in Fig.11.

It is concluded that, the energy cost reduces by more than $50 \%$ when both electrical grid and heating network are coupled together and the LCOE varies between $45-80 € / M W h$. The cost of energy from heat pump becomes higher than natural gas boiler after the renewable energy penetration $(\gamma \geq 1.3)$.

\subsection{Effect of selling excess generation}

Several studies have recommended the utilisation of excess generation in heating, transportation and aviation industry, as an ultimate solution for increasing penetration of renewable energy sources into the electrical grid. Rolando et al. 39 and Pensini et al. 22 have calculated the economic benefits with the electrification and concluded that selling excess generation from electrical grid becomes profitable after the price of $54 € / \mathrm{MWh}$.

Similarly, this analysis finds out that selling excess generation from the electrical grid to coupled heating network does not have major impact on LCOE of the system. It is calculated that, when both networks are coupled and the excess generation is sold at no extra cost, then the LCOE of the system is $45 € / \mathrm{MWh}$ and the cost-minimised design is possible at renewable energy penetration $\gamma=1$ and wind/solar mix $\alpha^{W}=0.85$. Furthermore, when the excess generation is sold at a price of 54 $€ / \mathrm{MWh}$, then the LCOE of system increases to $48.3 € / \mathrm{MWh}$, and the optimum renewable energy penetration $(\gamma)$ reduces to 0.7 and wind/solar mix $\left(\alpha^{W}\right)$ increases to 0.9 . The $54 € / \mathrm{MWh}$ is the limit when selling excess generation becomes profitable [39. However, when the excess generation is sold at a price of $108 € / \mathrm{MWh}$, then the LCOE of system increases to $49 € / \mathrm{MWh}$ and optimum renewable energy penetration $(\gamma)$ remains constant, whereas the wind/solar mix $\left(\alpha^{W}\right)$ reduces to 0.8 . These results are shown in Fig 12

These results show that selling excess generation does not have a major impact on the LCOE of system, until the integration of renewable energy increases to around twice the amount of electrical load i.e $\gamma=2$. This will be the case in future, but it is clear from this study that selling excess generation from electrical grid can be instrumental for the fossil-free future. 


\section{Conclusion}

This paper has presented a cost-optimum solution for the decarbonisation of heating network. The techno-economic feasibility analysis has been performed for the coupling of heating network with simplified fully renewable energy based electrical grid. This research extends the idea of highly renewable based electrical grid discussed in Ref. 39] and integrates heating network into it. The cost-minimised system configuration of this coupled network with optimum renewable energy penetration $(\gamma)$ and wind/solar mix $\left(\alpha^{W}\right)$ has been calculated by using real heat-consumption and heatproduction cost data.

The result for technically optimal network calculations explain that, the intra-day heat demand profile coincides with people commute to work. It is maximum at 9 am in the morning and lowest during the night. Moreover, designing thermal heat storage capacity according to $99 \%$ qualities of the thermal heat storage energy time-series distribution is found to be practically advantageous than designing natural gas boiler at mean of required energy time-series. Nevertheless, if the renewable energy penetration $(\gamma)$ is increased beyond $140 \%$ of the electrical load demand and wind/solar mix $\left(\alpha^{W}\right)$ is greater than $60 / 20$, then the backup generation capacity and natural gas boiler capacity becomes minimum and the capacity can be designed at mean backup heat energy time-series.

The economically optimal network calculations elaborate that, the LCOE for the fully renewable energy based stand-alone electrical grid and heating network is found to be minimum at $120 € / \mathrm{MWh}$ and $45 € / \mathrm{MWh}$, respectively. However, if both networks are coupled together at wind/solar mix $\left(\alpha^{W}\right)$ of $85 / 15$, then the LCOE can be reduced by more than $50 \%$ to $45 € /$ MWh rather than the current heat-production cost of $40 € / \mathrm{MWh}$ from the CHP plant.

The results from sensitivity analysis explain that, the LCOE and optimum wind/solar mix depends on the cost assumed for wind and solar PV power generation. Nevertheless, the optimum renewable energy penetration depends on the cost assumed for different heat-coupling technologies. It has been found that, the cost of energy from heat pump is found to be less than natural gas boiler until the renewable energy penetration of $130 \%$. The reduction in cost for wind and solar PV generation reduces the optimum renewable energy penetration $(\gamma)$ to $80 \%$ and optimum wind/solar mix $\left(\alpha^{W}\right)$ varies between $80 / 20$ - 94/6. However, the reduction in cost for heat-coupling technologies increases the optimum renewable energy penetration $(\gamma)$ between $120 \%$ $140 \%$ and optimum wind/solar mix $\left(\alpha^{W}\right)$ to $80 / 20$.

Finally, the carbon free future with heat-coupling is possible and beneficial for both sectors and the excess generation can be sold up to $108 € / \mathrm{MWh}$ without having major impact on LCOE of the coupled network. These findings can be instrumental to draw attention of policy makers towards economic viability of the fossil-free future heating network. It is envisioned that, the coupling of heating network will create more peaks of heat demand than the current conventional heating network, unless techniques such as, changing consumers behaviour, community engagement, demand side management, energy from other renewable energy sources or waste heat from the industry are used. It is recommended that, a detailed study is needed on techniques such as the low-temperature district heating [48, 49, uncertainty from extreme wind conditions and the integration of combination of large-scale heat pumps [50].

\section{Acknowledgments}

A.A is really grateful to Martin Greiner and Rolando A. Rodriguez from Aarhus University for providing data and helpful constructive discussions during this research. Moreover, Magnus Dahl for providing heat demand data of the Aarhus Municipality, Denmark.

\section{References}

[1] IEA, IRENA, Perspectives for the energy transition: Investment needs for a low-carbon energy system, Tech. rep., The International Energy Agency (IEA) and International Renewable Energy Agency (IRENA) (2017).

[2] J. G. O. (PBL), G. J.-M. (IES-JRC), M. M. (IESJRC), J. A. P. (PBL), Trends in global co2 emissions, Tech. rep., PBL Netherlands Environmental Assessment Agency, Institute for Environment and Sustainability (IES) of the European Commission's Joint Research Centre (JRC) (2015).

[3] McKinsey, KEMA, T. E. F. L. at Imperial College London, O. Economics, ECF, Roadmap 2050: A practical guide to a prosperous, low-carbon europe, Tech. rep., European Climate Foundation (2010).

[4] H. Lund, N. Duic, P. A. Østergaard, B. V. Mathiesen, Smart energy systems and 4 th generation district heating, Energy 110 (2016) 1 - 4. doi:10.1016/j.energy. 2016.07.105 
[5] N. Markovska, N. Duić, B. V. Mathiesen, Z. Guzović, A. Piacentino, H. Schlör, H. Lund, Addressing the main challenges of energy security in the twenty-first century - contributions of the conferences on sustainable development of energy, water and environment systems, Energy 115, Part 3 (2016) 1504 - 1512, sustainable Development of Energy, Water and Environment Systems. doi:10.1016/j.energy.2016.10.086

[6] D. Connolly, H. Lund, B. Mathiesen, S. Werner, B. Möller, U. Persson, T. Boermans, D. Trier, P. Østergaard, S. Nielsen, Heat roadmap europe: Combining district heating with heat savings to decarbonise the $\{\mathrm{EU}\}$ energy system, Energy Policy 65 (2014) $475-$ 489. doi:10.1016/j.enpol.2013.10.035

[7] H. Lund, J. Thellufsen, S. Aggerholm, K. Wittchen, S. Nielsen, B. Mathiesen, B. Möller, Heat saving strategies in sustainable smart energy systems, International Journal of Sustainable Energy Planning and Management 4 (0) (2015) 3-16. doi:10.5278/ij sepm.2014.4.2

[8] H. Lund, P. Østergaard, D. Connolly, I. Ridjan, B. Mathiesen, F. Hvelplund, J. Thellufsen, P. Sorknæs, Energy storage and smart energy systems, International Journal of Sustainable Energy Planning and Management 11 (0) (2016) 3-14. doi:10.5278/ijsepm.2016. 11.2.

[9] B. Mathiesen, H. Lund, D. Connolly, H. Wenzel, P. Østergaard, B. Möller, S. Nielsen, I. Ridjan, P. Karnøe, K. Sperling, F. Hvelplund, Smart energy systems for coherent $100 \%$ renewable energy and transport solutions, Applied Energy 145 (2015) 139 - 154. doi:10.1016/j.apenergy.2015.01.075

[10] D. Connolly, H. Lund, B. Mathiesen, Smart energy europe: The technical and economic impact of one potential $100 \%$ renewable energy scenario for the european union, Renewable and Sustainable Energy Reviews 60 (2016) 1634 - 1653. doi:10.1016/j.rser.2016.02.025

[11] K. Hansen, D. Connolly, H. Lund, D. Drysdale, J. Z. Thellufsen, Heat roadmap europe: Identifying the balance between saving heat and supplying heat-contributions of the conferences on sustainable development of energy, water and environment systems, Energy 115, Part 3 (2016) 1663 - 1671. doi:10.1016/j.energy. 2016.06 .033

[12] W. Xiong, Y. Wang, B. V. Mathiesen, H. Lund, X. Zhang, Heat roadmap china: New heat strategy to reduce energy consumption towards 2030, Energy 81 (2015) $274-285$. doi:10.1016/j.energy.2014.12.039

[13] U. Persson, B. Möller, S. Werner, Heat roadmap europe: Identifying strategic heat synergy regions, Energy Policy 74 (2014) 663 - 681. doi:10.1016/j.enpol.2014. 07.015

[14] B. Möller, S. Nielsen, High resolution heat atlases for demand and supply mapping, International Journal of Sustainable Energy Planning and Management 1 (2014) 41-58. doi:10.5278/ijsepm.2014.1.4

[15] A. Ashfaq, Z. H. Kamali, M. H. Agha, H. Arshid, Heat coupling of the pan-european vs. regional electrical grid with excess renewable energy, Energy 122 (2017) 363 377. doi:10.1016/j.energy.2017.01.084

[16] S. Petrovic, K. Karlsson, Use of danish heat atlas and energy system models for exploring renewable energy scenarios, in: Proceedings of the 8th Conference on Sustainable Development of Energy, Water and Environment Systems (SDEWES 2013).

[17] L. Grundahl, S. Nielsen, H. Lund, B. Möller, Compar- ison of district heating expansion potential based on consumer-economy or socio-economy, Energy 115, Part 3 (2016) 1771 - 1778. doi:10.1016/j.energy.2016.05. 094.

[18] D. Dominković, I. Bačeković, D. Sveinbjörnsson, A. Pedersen, G. Krajačić, On the way towards smart energy supply in cities: The impact of interconnecting geographically distributed district heating grids on the energy system, Energy (2017) doi:10.1016/j.energy . 2017.02 .162

[19] J. Z. Thellufsen, H. Lund, Energy saving synergies in national energy systems, Energy Conversion and Management 103 (2015) 259 - 265. doi:10.1016/j. enconman.2015.06.052

[20] R. A. Rodríguez, S. Becker, G. B. Andresen, D. Heide, M. Greiner, Transmission needs across a fully renewable european power system, Renewable Energy 63 (2014) 467 - 476. doi:10.1016/j.renene.2013.10.005

[21] J. Z. Thellufsen, H. Lund, Cross-border versus crosssector interconnectivity in renewable energy systems, Energy 124 (2017) 492 - 501. doi:10.1016/j.energy. 2017.02.112

[22] A. Pensini, C. N. Rasmussen, W. Kempton, Economic analysis of using excess renewable electricity to displace heating fuels, Applied Energy 131 (2014) 530 - 543. doi:10.1016/j.apenergy.2014.04.111

[23] S. Bofinger, L. von Bremen, K. knorr, K. lesch, K. Rohrig, Y.-M. Saint-Drenan, M. Speckmann, "raumzeitliche erzeugungsmuster von wind- und solarenergie in der ucte region und deren einfluss auf elektrische transportnetze.", Tech. rep., Institut für Solare Energieversorgungstechnik, ISET e.V.; (November, 2008).

[24] U. Rasmussen, Water consumption in the energy sector and energy consumption in the water-sector in a danish municipality., Journal of Transdisciplinary Environmental Studies 11 (1) (2012) $3-5$.

[25] S. Suranjana, M. Shrinivas, P. Hua-Lu, W. Xingreni, W. Jiande, N. Sudhir, The NCEP Climate Forecast System Reanalysis, Bulletin of the American Meteorological Society 91 (8) (2010) 1015-57. doi:10.1175/ 2010BAMS3001.1

[26] S. Saha, S. Moorthi, X. Wu, J. Wang, S. Nadiga, P. Tripp, D. Behringer, Y.-T. Hou, H. ya Chuang, M. Iredell, M. Ek, J. Meng, R. Yang, M. P. Mendez, H. van den Dool, Q. Zhang, W. Wang, M. Chen, E. Becker, Ncep climate forecast system version 2 (cfsv2) selected hourly time-series products, Bulletin of the American Meteorological Societydoi:10.5065/ D6N877VB

[27] C. for International Earth Science Information Network Columbia University (CIESIN), C. I. de Agricultura Tropical (CIAT), Gridded population of the world, version 3 (gpwv3): Population density grid, future estimates (20160603 2005).

[28] D. Connolly, K. Hansen, D. Drysdale, H. Lund, B. V. Mathiesen, S. Werner, U. Persson, B. Möller, O. G. Wilke, K. Bettgenhäuser, W. Pouwels, T. Boermans, T. Novosel, G. Krajačić, N. Duić, D. Trier, D. Møller, A. M. Odgaard, L. L. Jensen, Stratego: Enhanced heating and cooling plans to quantify the impact of increased energy efficiency in eu member states, Tech. rep., Aalborg University, Denmark (2015).

[29] P. Zangheri, R. Armani, M. Pietrobon, L. Pagliano, Heating and cooling energy demand and loads for building types in different countries of the eu, Tech. rep., 
End-use Efficiency Research Group (eERG), Politecnico di Milano, Maria Fernandez Boneta (CENER), National Renewable Energy Centre, Andreas Müller (EEG), Vienna University of Technology (2014).

[30] D. Heide, L. von Bremen, M. Greiner, C. Hoffmann, M. Speckmann, S. Bofinger, Seasonal optimal mix of wind and solar power in a future, highly renewable europe, Renewable Energy 35 (11) (2010) 2483 - 2489. doi: 10.1016/j.renene.2010.03.012

[31] G. B. Andresen, R. A. Rodriguez, S. Becker, M. Greiner, The potential for arbitrage of wind and solar surplus power in denmark, Energy 76 (0) (2014) 49 - 58. doi:10.1016/j.energy.2014.03.033

[32] M. G. Rasmussen, G. B. Andresen, M. Greiner, Storage and balancing synergies in a fully or highly renewable pan-european power system, Energy Policy 51 (2012) $642-651$, renewable Energy in China. doi:10.1016/ j.enpol.2012.09.009

[33] D. Heide, M. Greiner, L. von Bremen, C. Hoffmann, Reduced storage and balancing needs in a fully renewable European power system with excess wind and solar power generation, Renewable Energy 36 (9) (2011) 2515 - 2523. doi:10.1016/j.renene.2011.02.009

[34] S. Becker, R. Rodriguez, G. Andresen, S. Schramm, M. Greiner, Transmission grid extensions during the build-up of a fully renewable pan-european electricity supply, Energy 64 (2014) $404-418$. doi:10.1016/j. energy.2013.10.010

[35] M. Dahl, Power-Flow Modeling in Complex Renewable Electricity Networks, Master's thesis, Aarhus University, Denmark (2015).

[36] S. Becker, B. A. Frew, G. B. Andresen, T. Zeyer, S. Schramm, M. Greiner, M. Z. Jacobson, Features of a fully renewable $\{\mathrm{US}\}$ electricity system: Optimized mixes of wind and solar $\{\mathrm{PV}\}$ and transmission grid extensions, Energy 72 (2014) $443-458$. doi: 10.1016/j.energy.2014.05.067

[37] S. Becker, B. A. Frew, G. B. Andresen, M. Z. Jacobson, S. Schramm, M. Greiner, Renewable build-up pathways for the us: Generation costs are not system costs, Energy 81 (2015) 437 - 445. doi:10.1016/j.energy. 2014. 12.056

[38] D. Schlachtberger, S. Becker, S. Schramm, M. Greiner, Backup flexibility classes in emerging large-scale renewable electricity systems, Energy Conversion and Managementdoi:10.1016/j.enconman.2016.04.020

[39] R. A. Rodriguez, S. Becker, M. Greiner, Cost-optimal design of a simplified, highly renewable pan-european electricity system, Energy 83 (2015) 658 - 668. doi: $10.1016 / j$.energy.2015.02.066

[40] M. A. Delucchi, M. Z. Jacobson, Providing all global energy with wind, water, and solar power, part ii: Reliability, system and transmission costs, and policies, Energy Policy 39 (3) (2011) 1170 - 1190. doi: 10.1016/j.enpol.2010.11.045

[41] C. Budischak, D. Sewell, H. Thomson, L. Mach, D. E. Veron, W. Kempton, Cost-minimized combinations of wind power, solar power and electrochemical storage, powering the grid up to $99.9 \%$ of the time, Journal of Power Sources 225 (2013) 60 - 74. doi:10.1016/j. jpowsour.2012.09.054

[42] M. Z. Jacobson, M. A. Delucchi, Providing all global energy with wind, water, and solar power, part i: Technologies, energy resources, quantities and areas of infrastructure, and materials, Energy Policy 39 (3) (2011)
1154 - 1169. doi:10.1016/j.enpol.2010.11.040

[43] O. Arup, P. Ltd, Review of the generation costs and deployment potential of renewable electricity technologies in the uk, Tech. rep., Department of Energy and Climate Change (2011).

[44] EIA, U.S. Energy Information Administration, Levelized Cost and Levelized Avoided Cost of New Generation Resources in the Annual Energy Outlook 2015 (2015).

[45] M. Fürsch, C. Golling, M. Nicolosi, R. Wissen, D. D. Lindenberger, European res-e policy analysis, Tech. rep., Institute of Energy Economics at the University of Cologne (2010).

[46] D. Steward, G. Saur, M. Penev, T. Ramsden, Lifecycle cost analysis of hydrogen versus other technologies for electrical energy storage, NREL.

[47] K. Schaber, F. Steinke, P. Mühlich, T. Hamacher, Parametric study of variable renewable energy integration in europe: Advantages and costs of transmission grid extensions, Energy Policy 42 (2012) 498 - 508. doi:10.1016/j.enpol.2011.12.016

[48] H. Lund, S. Werner, R. Wiltshire, S. Svendsen, J. E. Thorsen, F. Hvelplund, B. V. Mathiesen, 4th generation district heating (4gdh): Integrating smart thermal grids into future sustainable energy systems, Energy 68 (2014) 1 - 11. doi:10.1016/j.energy . 2014.02.089

[49] A. Ianakiev, J. M. Cui, S. Garbett, A. Filer, Innovative system for delivery of low temperature district heating, International Journal of Sustainable Energy Planning and Management 12 (0) (2017) 19-28. doi:10.5278/ ijsepm.2017.12.3

[50] B. Bach, J. Werling, T. Ommen, M. Münster, J. M. Morales, B. Elmegaard, Integration of large-scale heat pumps in the district heating systems of greater copenhagen, Energy 107 (2016) 321 - 334. doi:10.1016/j. energy.2016.04.029 


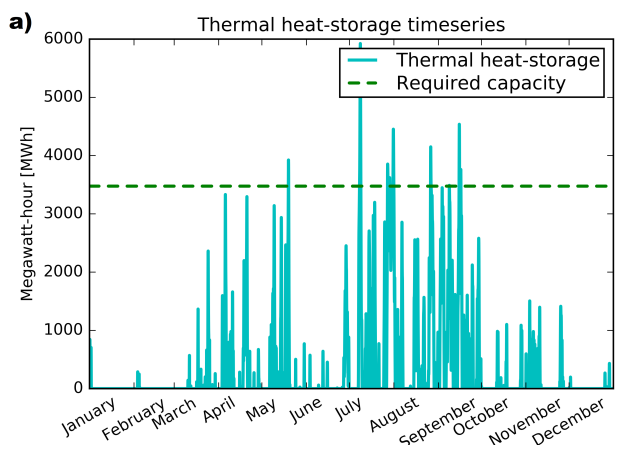

b)

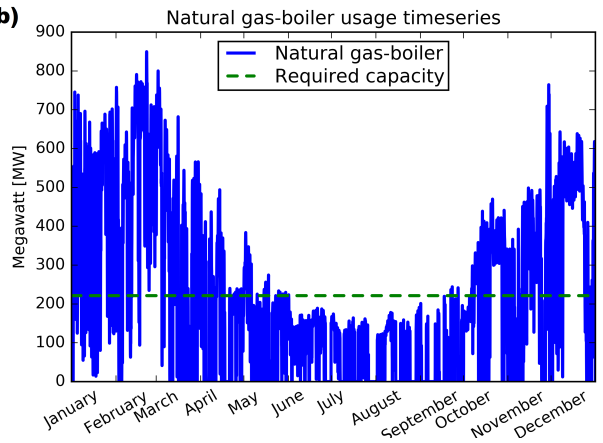

c) Thermal heat-storage capacity $\mathcal{K}^{E}$

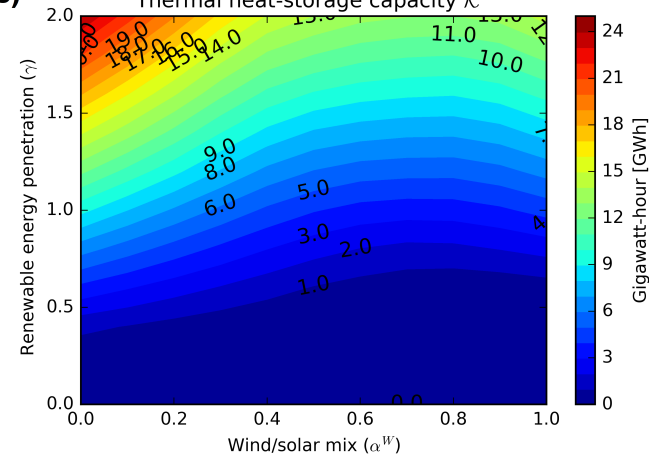

d)

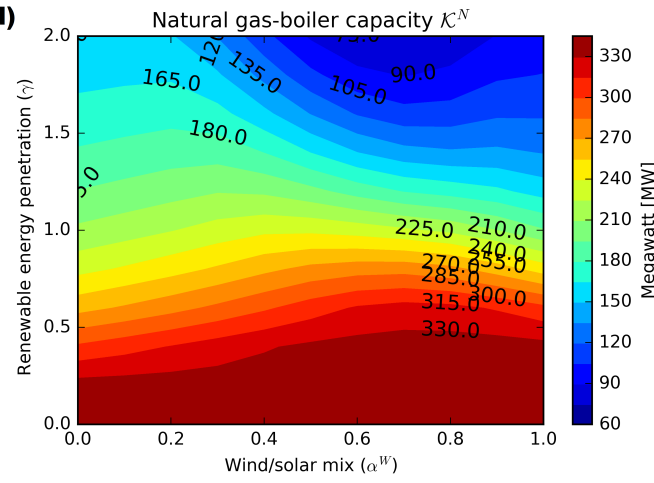

Figure 5: Panels $(\mathrm{a}, \mathrm{c})$ show required thermal heat storage capacity $\left(\mathcal{K}^{E}\right)$ and panels $(\mathrm{b}, \mathrm{d})$ show required natural gas boiler capacity $\left(\mathcal{K}^{N}\right)$ with different combinations of renewable energy penetration $(\gamma)$ and wind/solar $\operatorname{mix}\left(\alpha^{W}\right)$. The panels $(\mathrm{a}, \mathrm{b})$ depict results with calculation at renewable energy penetration $(\gamma=1)$ and wind/solar mix $\left(\alpha^{W}=0.8\right)$. The $\mathcal{K}^{E}$ and $\mathcal{K}^{N}$ is calculated by using Eqs. 15,17 , respectively.
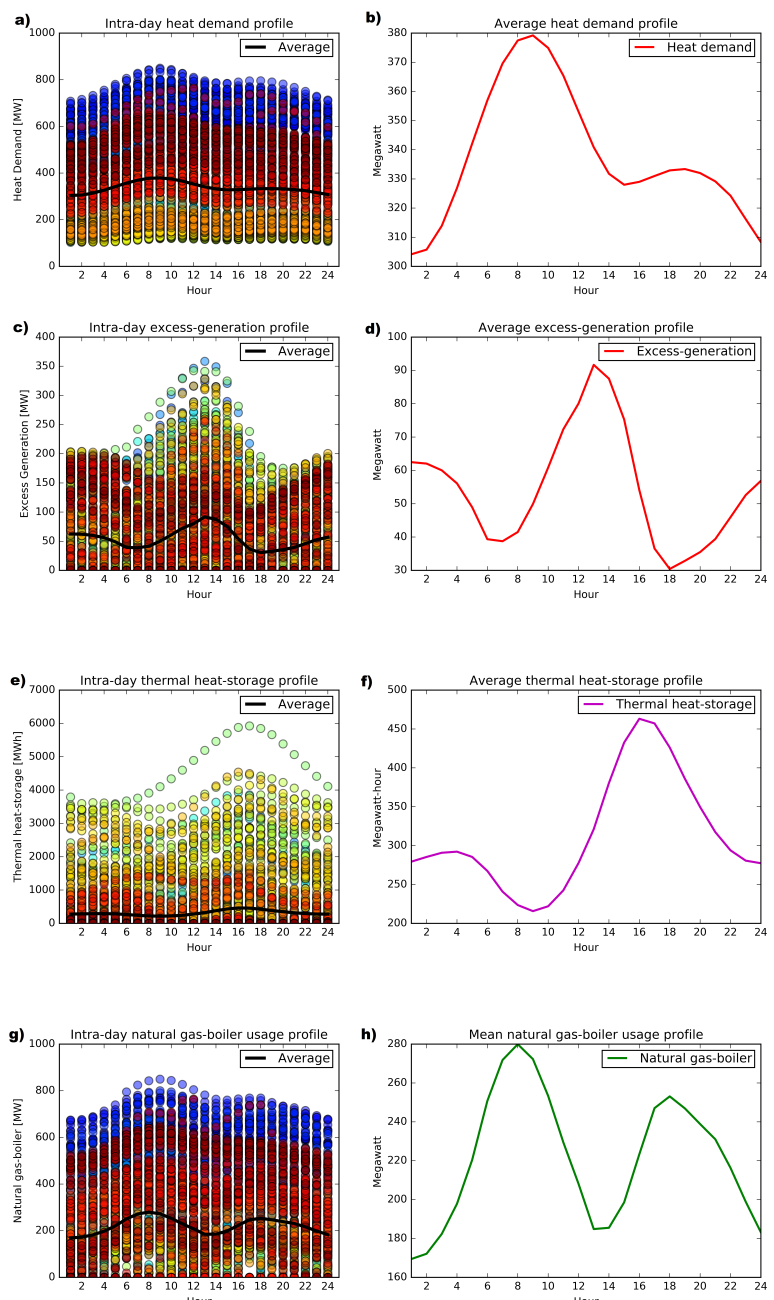

Figure 6: Intra-day and average demand profiles for Aarhus, Denmark with heat pump coupling. Panles. (a, c, e, g) show intra-day demand profile for all 365 days throughout the year, whereas panels. (b, d, f, h) show the average annual demand profile. ( 0 being the first day and 365 as last day of the year). (For interpretation and reference to the legends in this figure, the reader is referred to the web version of this article.) 

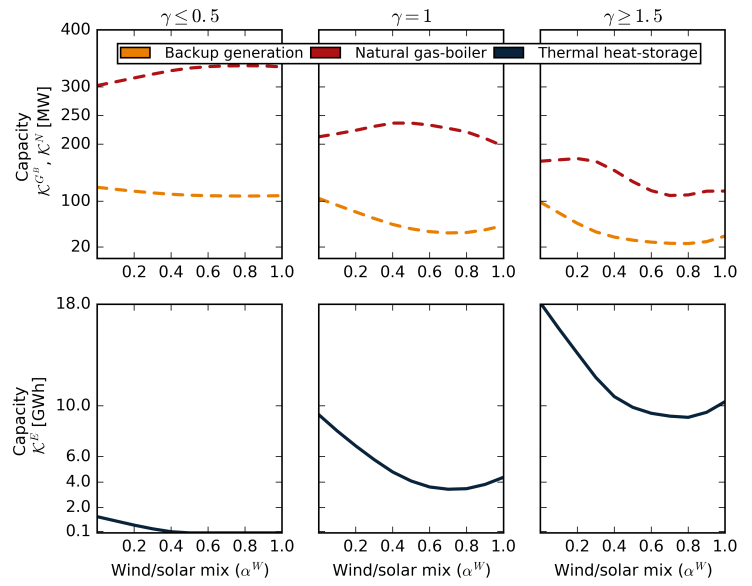

Figure 7: Backup generation capacity $\left(\mathcal{K}^{B}\right)$, natural gas boiler capacity $\left(\mathcal{K}^{N}\right)$ and thermal heat storage capacity $\left(\mathcal{K}^{E}\right)$ calculated by using Eqs. 14 15. 17, as a function of renewable energy penetration $(\gamma)$ and wind/solar mix $\left(\alpha^{W}\right)$. Columns represent renewable energy penetration: left column $(\gamma=0.5)$, middle column $(\gamma=1.0)$ and right column $(\gamma=1.5)$. Whereas, first row represents the $\mathcal{K}^{B}$ and $\mathcal{K}^{N}$ in $M W$. The second row represents the $\mathcal{K}^{E}$ in $G W h$.
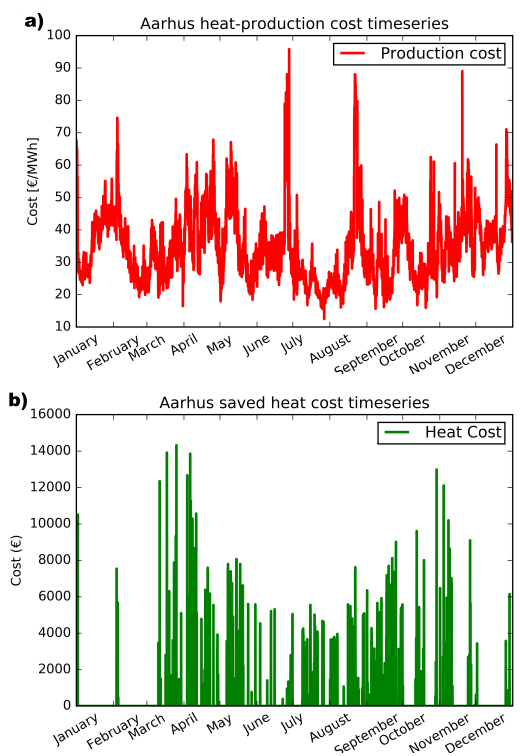

Figure 8: Panel (a) shows hourly heat-production cost for the city of Aarhus. Panel (b) shows the cost of heat that can be saved by using heat pump coupling, calculated at renewable energy penetration $(\gamma=1)$ and wind/solar mix $\left(\alpha^{W}=0.8\right)$.
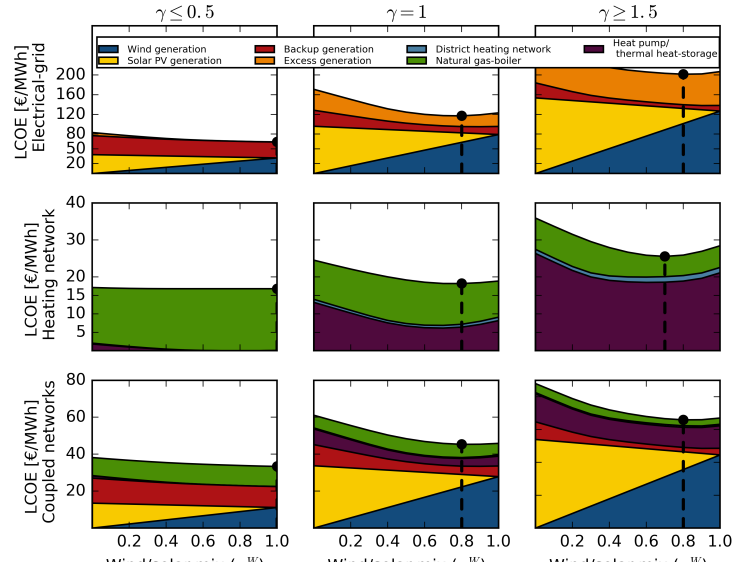

Figure 9: Levelised cost of energy ( $€ / M W h)$ for energy required by the system with different proportions of renewable energy penetration $(\gamma)$ and wind/solar mix $\left(\alpha^{W}\right)$. Columns represent renewable energy penetration: left column $(\gamma=$ $0.5)$, middle column $(\gamma=1.0)$ and right column $(\gamma=1.5)$. Whereas, rows represent different networks: fully renewable energy based stand-alone electrical grid (top row), renewable based heating network with heat-coupling (middle row) and heat coupled network. (For interpretation and reference to the legends in this figure, the reader is referred to the web version of this article.) 

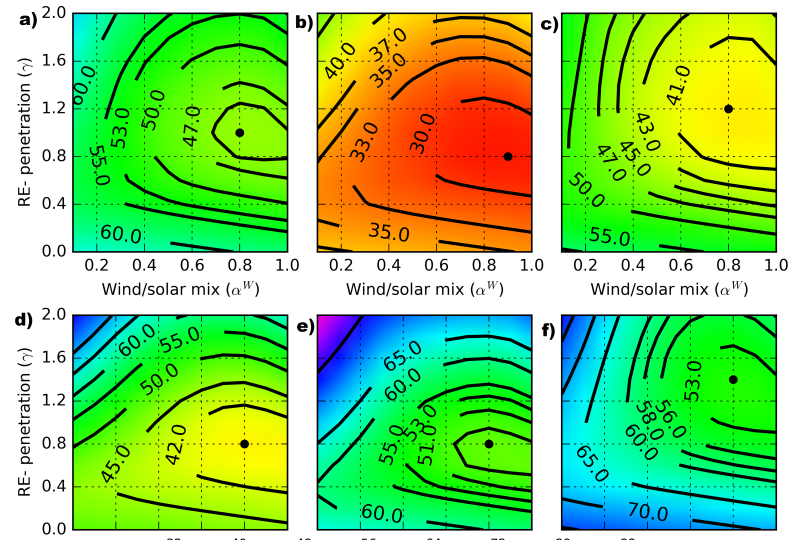

Wind/solar mix $\left(\alpha^{W}\right)$

Wind/solar mix $\left(\alpha^{W}\right)$

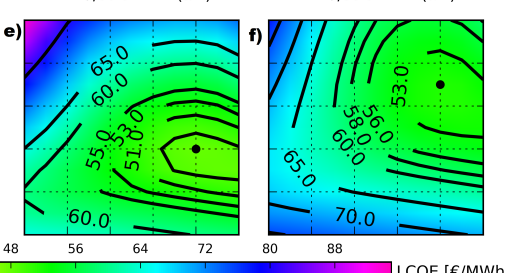

Figure 10: Levelised cost of energy ( $€ / M W h)$ with different cost assumptions (CapEx and OpEX) as a function of renewable energy penetration $(\gamma)$ and wind mix $\alpha^{W}$ : panel (a) show results with initial cost assumptions, (b) show results with $50 \%$ decrease in the cost of electrical grid (wind generation, solar PV generation, backup generation), (c) show results with $50 \%$ decrease in the cost of heating network (heat pump, thermal heat storage, district heating network and natural gas boiler) and (d) show results with $50 \%$ decrease in the cost of electrical grid (wind generation, solar PV generation, backup generation) and 50\% increase in the cost of heating network (heat pump, thermal heat storage, district heating network and natural gas boiler), (e) show results with $50 \%$ increase in the cost of heat pump, and (f) show results with $50 \%$ increase in the cost of natural gas boiler. (Dark dots depict the cost-minimised solution). (For interpretation and reference to the legends in this figure, the reader is referred to the web version of this article.)

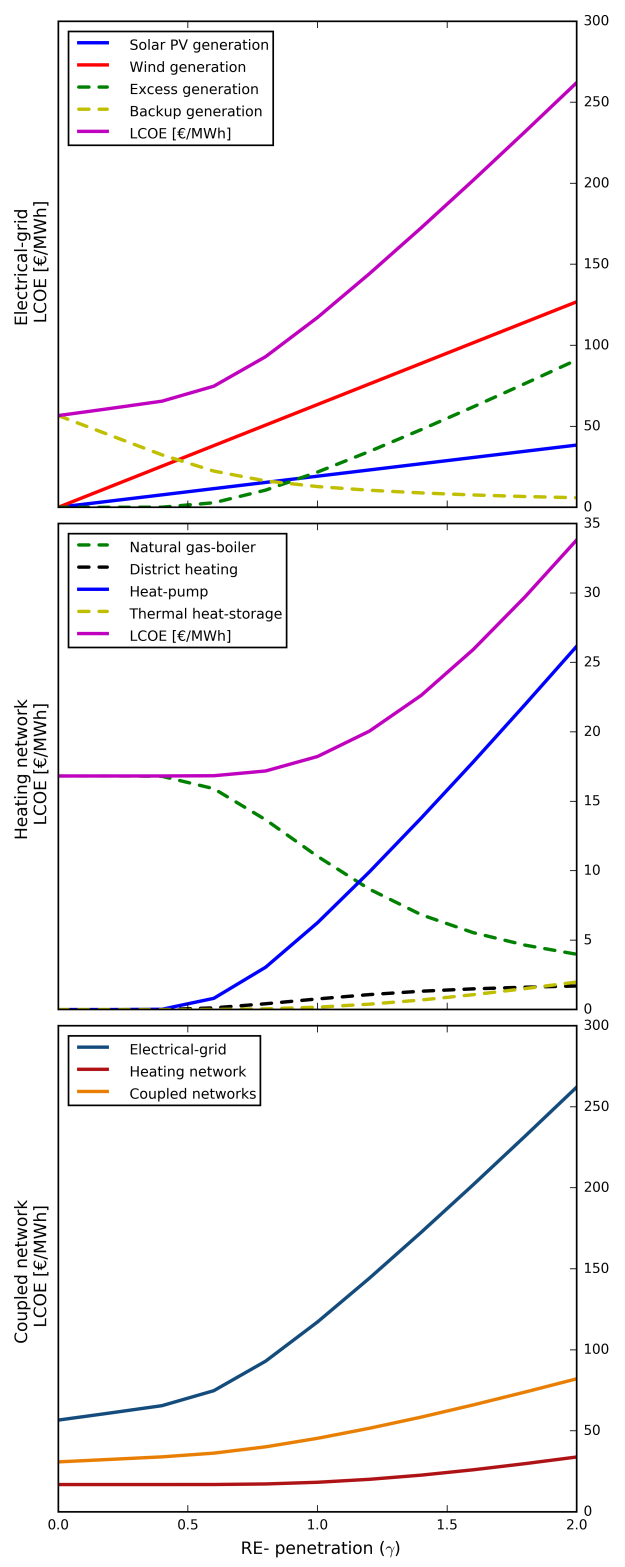

Figure 11: Levelised cost of energy ( $€ / M W h)$ with the increase in renewable energy penetration $(\gamma)$ at wind/solar mix $\left(\alpha^{W}=0.80\right)$. Top figure depicts the fully renewable based stand-alone electrical grid, middle figure depicts the renewable based heating network and bottom figure depicts when both networks are coupled together. 


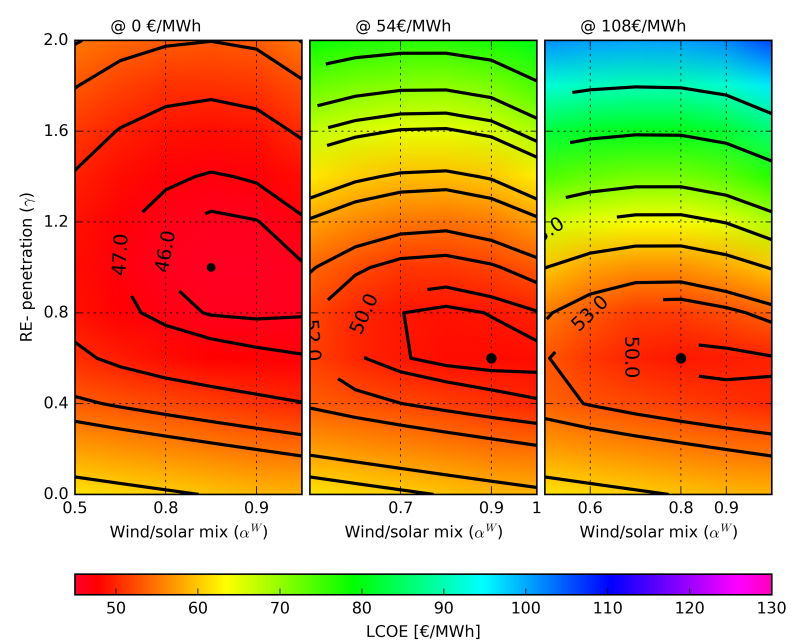

Figure 12: Levelised cost of energy (€/MWh) with different prices excess generation, as a function of renewable energy penetration $(\gamma)$ and wind/solar mix $\left(\alpha^{W}\right)$. Left column show results when the excess generation is sold at no extra cost. Middle column show results when the excess generation is sold at price of $54 € / \mathrm{MWh}$ and right column show results when excess generation is sold at price of $108 € /$ MWh.(Dark dots depict the cost-minimised solution). (For interpretation and reference to the legends in this figure, the reader is referred to the web version of this article.) 